\title{
Injury management programme at SA Rugby youth tournaments
}

As this edition of the journal goes to press, the annual rugby youth tournaments begin around the country. These national tournaments provide an opportunity for the best young rugby players in the country to showcase their skills. In addition to catering for players of the under-13, -16 and -18 age groups, there is also a tournament for players from schools with special needs. The tournaments provide an opportunity for talent scouts representing schools, provinces and rugby academies to examine the skills of the players and offer contracts to those who they consider to be special.

Rugby is a sport involving collisions between players, and sometimes, when they are sprinting at maximum speed, injuries are inevitable. It is for this reason that the medical division of SA Rugby and BokSmart ${ }^{[1]}$ initiated a programme to attempt to make the game safer. They have provided medical facilities at each tournament venue, and for the last 3 years, have had staff to record every injury treated by the doctor at each tournament. The information about each injury is entered into a database and analysed. ${ }^{[2]}$ The information includes the type of injury, body part injured, mechanism of injury, stage and phase of the game when the injury occurred. The field conditions are also noted. Parents of injured players are contacted regularly after the tournament, until the injury has repaired. The aim is to quantify the severity of the injuries and medical services required for each tournament. This information will also support a project that is currently underway to calculate the financial cost of each injury. By providing accurate information to the actuaries of medical insurance companies, it will be possible to calculate an insurance package specifically designed for the tournament. This is particularly relevant as nearly a quarter of the players attending the tournaments do not have medical aid to cover their expenses in the event of an injury.

Also, at two tournaments (under-18 Academy Week and Club Championships) the players are requested to complete a questionnaire probing their knowledge, attitude and behaviour regarding injuries. This serves to identify key areas that need to be addressed and tracks changes in knowledge, attitude and behaviour from year to year.

This shows that SA Rugby is aspiring to principles of 'best practice' in trying to manage the game efficiently from an injury perspective. By implementing a sophisticated data-collection programme, the organisation is able to measure the problem of injuries in its youth players and consequently position itself to manage these injuries. This means that medical services at each tournament can be planned more accurately, and the organisation is well-positioned to detect any trends in injuries that may emerge as a result of rule changes.

The programme that SA Rugby has put in place is not 'rocket science'; it has merely been implemented in a systematic way using measurement tools devised though a process of international consensus. ${ }^{[3]}$ Emphasis has been placed on collecting data in a methodical way, and data analysis is an ongoing process. There is no reason why the other sporting codes cannot implement similar programmes. Consensus documents describing definitions of injuries and methodological recommendations for $\operatorname{cricket}^{[4]}$ and soccer ${ }^{[5]}$ have been published; therefore, the next step requires a decision by management to measure and analyse the data for these sports. When all major sports have embraced this approach, there is a strong possibility that they will become safer for their participants. When participants see that the administrators are 'upping their game', there is a very good chance that they will respond with superior playing performances.

The articles in this edition of the journal cover a broad scope, ranging from the effects of exercise on mood in breast cancer patients, ${ }^{[6]}$ to the risk of cardiac arrest in young athletes. ${ }^{[7]}$ There are also two articles on injuries associated with long-distance running, ${ }^{[8,9]}$ an article on the fitness of women rugby players ${ }^{[10]}$ and, finally, a study on the effects of over-the-counter dosages of pseudoephedrine on swimming performance. ${ }^{[1]}$ Enjoy the read!

\section{Mike Lambert}

Editor-in-Chief

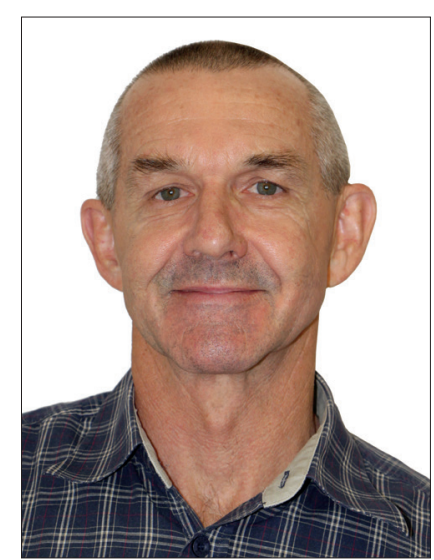

1. Viljoen W, Patricios J. BokSmart - implementing a National Rugby Safety Programme. Br J Sports Med 2012 May 19;46(10):692-693. [http://dx.doi.org/10.7196/SAJSM.460]

2. Brown J, Verhagen E, Viljoen W, et al. The incidence and severity of injuries at the 2011 South African Rugby Union (SARU) Youth Week tournaments. South African Journal of Sports Medicine 2012;24(2):49-54.

3. Fuller CW, Molloy MG, Bagate C, et al. Consensus statement on injury definitions and data collection procedures for studies of injuries in rugby union. Br J Sports Med 2007;41(5):328-331. [http://dx.doi.org/10.1136/bjsm.2006.033282]

4. Orchard J, Newman D, Stretch R, Frost W, Mansingh A, Leipus A. Methods for injury surveillance in international cricket. Journal of Science and Medicine in Sport 2005;8(1):1-14. [http://dx.doi.org/10.1016/S1440-2440(05)80019-2]

5. Junge A, Dvorak J. Influence of definition and data collection on the incidence of injuries in football. Am J Sports Med 2000;28(5 Suppl):S40-46.

6. Van Oers HM. Exercise effects on mood in breast cancer patients. South African Journal of Sports Medicine 2013;25(2):55-59. [http://dx.doi.org/10.7196/SAJSM.481]

7. Gradidge PJ-L, Constantinou D, Goldberg L. Sudden cardiac arrest risk in young athletes. South African Journal of Sports Medicine 2013;25(2):53-54. [http://dx.doi. org/10.7196/SAJSM.469]

8. Ellapen TJ, Satyendra S, Morris J, van Heerden HJ. Common musculoskeletal injuries among recreational half-marathon runners in KwaZulu-Natal. South African Journal of Sports Medicine 2013;25(2):39-43. [http://dx.doi.org/10.7196/SAJSM.360]

9. Kellogg DS, Joslin J. The legend of plantar neuropraxia in long-distance athletes. South African Journal of Sports Medicine 2013;25(2):51-52. [http://dx.doi.org/10.7196/ SAJSM.468]

10. Hene NM, Bassett SH. Changes in the physical fitness of elite women's rugby union players over a competitive season. South African Journal of Sports Medicine 2013;25(2):47-50. [http://dx.doi.org/10.7196/SAJSM.371]

11. Gradidge PJ-L, Constantinou D, Heard S-M, King C, Morris-Eyton H. Effect of a therapeutic dose of pseudoephedrine on swimmers' performance. South African Journal of Sports Medicine 2013;25(2):43-36. [http://dx.doi.org/10.7196/SAJSM.378]

S Afr J SM 2013;25(2):38. DOI:10.7196/SAJSM.493 